\title{
Museo de Arte de El Salvador: un esfuerzo compartido
}

El Museo de Arte de El Salvador, Marte, es la realización de un sueño que, por varios años, muchos soñamos. En este empeño es justo destacar el trabajo desarrollado por Julia Díaz, quien puso todo su entusiasmo para lograrlo. El resultado de sus esfuerzos fue el Museo Forma, inaugurado en 1983. Veinte años después, el 22 de mayo de 2003 el Marte abrió sus puertas. Para hacer realidad esta nueva institución el Patronato Pro Cultura de El Salvador, en 1998, empezó a desarrollar la idea, al tiempo que hacía gestiones para obtener el terreno donde construirlo.

Las razones que prevalecieron en la selección de la futura ubicación del museo fueron de índole artística, ya que frente al área donde se podía edificar se encuentra el "Monumento a la Revolución", el cual es un conjunto artístico-arquitectónico diseñado por los arquitectos Óscar Reyes y Kurt Shulzs, diseño que fue seleccionado mediante un concurso. Construido en la década de 1950 el monumento contiene, en una estructura vertical en forma de teja, un mosaico en piedra, realizado por el artista mexicano Claudio Cevallos Leal y por la artista salvadoreña Violeta Bonilla (1926-1999). Respecto a las características del mosaico, fechado en 1954, es importante destacar que las piedras con sus tonos naturales que lo conforman fueron recolectadas en todo el país y que con ellas fue construida la figura de un hombre desnudo, que mira hacia arriba y que tiene los brazos extendiéndose hacia el cielo.

Además, en ese lugar se encuentra un conjunto escultórico monumental obra de Francisco Zúñiga (1913-1993) artista de origen costarricense que vivió y produjo gran parte de su obra en México, donde se nacionalizó y desde donde se convirtió en uno de los más importantes escultores latinoamericanos. Dicho conjunto escultórico, fechado en 1956, es una alegoría a la Constitución de 1950 y esta formado por nueve figuras: un obrero, una madre que sostiene en sus brazos a su hijo, la figura de una niña, dos figuras femeninas, una de 


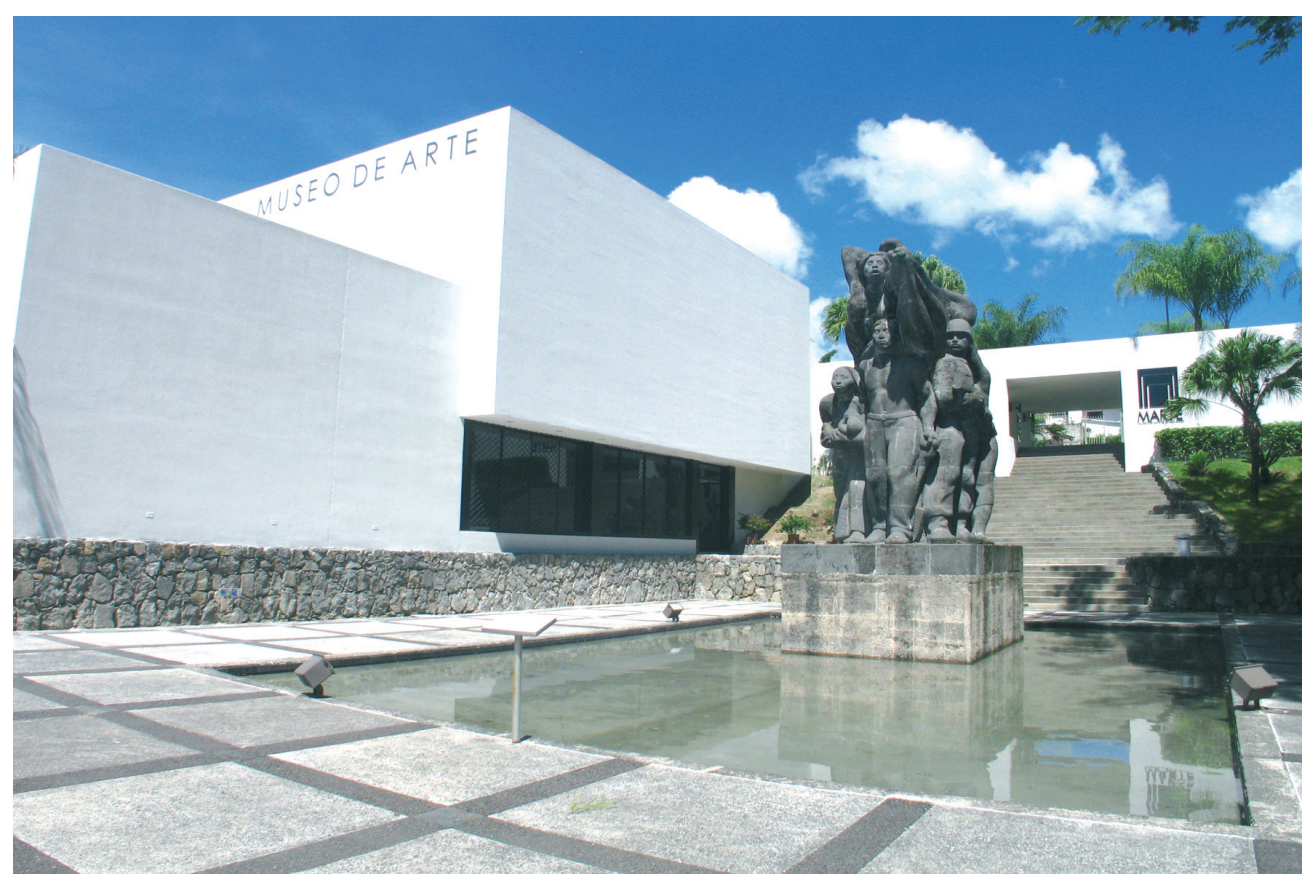

Museo de Arte de El Salvador, Marte

ellas parcialmente cubierta por un soldado, el cual sostiene su fusil apuntando hacia abajo en actitud pacífica. En la pare posterior destaca una mujer que sujeta un ejemplar de la Carta Magna. Todas estas figuras sostienen otra mujer cubierta con la bandera de El Salvador.

Gracias al interés del doctor Armando Calderón Sol, en ese entonces presidente de la República (1994-1999) y al de su esposa, licenciada Elizabeth de Calderón Sol, se logró obtener el terreno seleccionado, lo que garantizó el rescate del monumento y su integración al futuro museo. En la actualidad el mencionado monumento se encuentra en la última etapa de restauración gracias al apoyo recibido, en diferentes momentos, por la institución cultural del Estado.

Con la aprobación del Decreto Legislativo 664 de fecha 26 de agosto de 1999 , publicado en el Diario Oficial No. 157, Tomo No. 344, de un comodato por 99 años otorgado por la Honorable Asamblea Legislativa, se dio término a los trámites legales y el proyecto del museo fue asumido por la Asociación Museo de Arte de El Salvador, institución creada con ese propósito. Su personería jurídica la obtuvo mediante acuerdo ejecutivo 338, publicado en el Diario Oficial No. 89, del 6 de mayo de 2000. Desde antes de esa fecha hasta 
el momento, la junta directiva de la Asociación, presidida por María Marta de Regalado, ha desarrollado una notable labor. Este trabajo fue reconocido por el Gobierno de la República al otorgarle, en el 2003, el Premio Nacional de Cultura en el área de Gestión Cultural. Este compromiso lo mantiene con vistas al futuro, con el fin de garantizar la permanencia de nuestra institución.

El diseño del museo le fue encomendado al arquitecto salvadoreño Salvador Choussy, quien lo concibió con la integración del "Monumento a la Revolución", convirtiéndolo en una plaza monumental que sirve de acceso a las instalaciones, compuestas por un sobrio edificio de tres niveles con un área de $2.968 \mathrm{~m}^{2}$, de estos más de la mitad esta destinada a las exposiciones. Dos salas son exclusivas para exposiciones temporales, tres dedicadas al arte salvadoreño y tres espacios adicionales para exposiciones itinerantes y otros proyectos que desarrolla el museo, como lo son los programas "Artista del mes", "De nuestra colección” y "Marte contemporáneo". Aparte de esta área pública, el museo cuenta con otros espacios dedicados a ofrecer servicios adicionales a los visitantes (tienda y restaurante, salón audiovisual y salón de usos múltiples). El área administrativa, talleres y los depósitos cuentan con espacios adecuados.

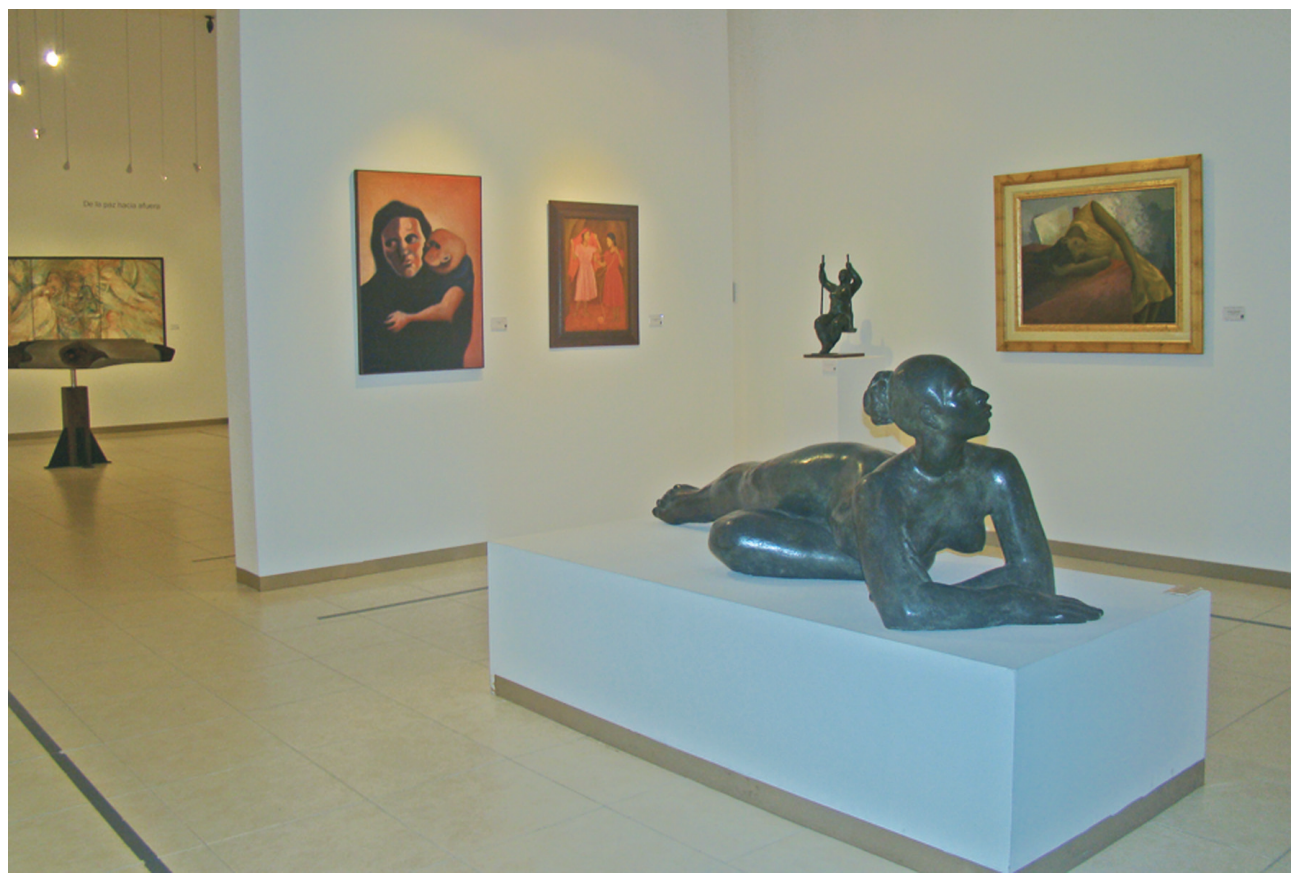

Sala de exhibición permanente, Marte 
En la actualidad el edificio del Marte - que fue ampliado en el 2007- se descubre en toda su magnitud en cuanto se ingresa. En el área de recepción se le expresan agradecimientos a las personas, empresas e instituciones que contribuyeron a su construcción, así como a aquellas que han asumido el compromiso de garantizar su funcionamiento mediante su integración al programa "Pilares de Marte", y a todos los que, deseosos de colaborar, son miembros o amigos del Marte. Después se pasa por el vestíbulo que comunica con el área de exhibición. En ese mismo nivel, a mano izquierda, esta el área dedicada a las exposiciones temporales; y bajando por las gradas o la rampa se llega a las tres salas que están dedicadas al arte salvadoreño, entre las que se destaca la Gran Sala, cuyo espacio impresiona por su limpieza formal y sus dimensiones. El edificio, bañado por luz cenital en dos de sus áreas, alterna los espacios cerrados dedicados a la contemplación con áreas luminosas que envuelven a nuestros visitantes y los comunica con el espacio exterior.

El Marte, en su corto tiempo de existencia, gracias al intenso trabajo desarrollado desde su apertura, es uno de los proyectos culturales más exitosos de nuestro país y es un referente en la vida cultural de la región centroamericana. Sus vínculos con muchas instituciones extranjeras afines y las importantes exhibiciones realizadas lo han proyectado internacionalmente. Esta tarea, nada fácil, permitirá, en el futuro, ofrecer nuevas exhibiciones y poner al alcance de todos los salvadoreños obras de artistas reconocidos a escala mundial y abrir nuevos horizontes para el arte nacional.

En el 2010 se cumplirán diez años de la creación de la Asociación Museo de Arte de El Salvador y siete de la apertura del museo. La seriedad y profesionalismo con el que se ha trabajado nos hacen olvidar que estos pocos años en la vida de un museo son muy significativos. El trabajo apenas comienza. Por eso siempre tenemos presente, todos los que trabajamos impulsando esta gran obra, que para hacerla realidad fue necesario sumar los generosos esfuerzos del sector privado con el apoyo del sector público, en el que intervinieron diferentes instituciones gubernamentales, entre las que se destaca la participación del Consejo Nacional para la Cultura y el Arte, Concultura, (hoy Secretaría de Cultura), cuyo compromiso institucional dio inicio el 11 de junio de 1998, cuando se suscribió un documento con el Patronato Pro Cultura en un acto celebrado en el Teatro Nacional de San Salvador, mediante el cual ambas entidades se comprometieron a impulsar este proyecto.

Poco antes de cumplir con su mandato, le correspondió al licenciado Francisco Flores, quien se desempeñó como presidente de la República entre 1999- 


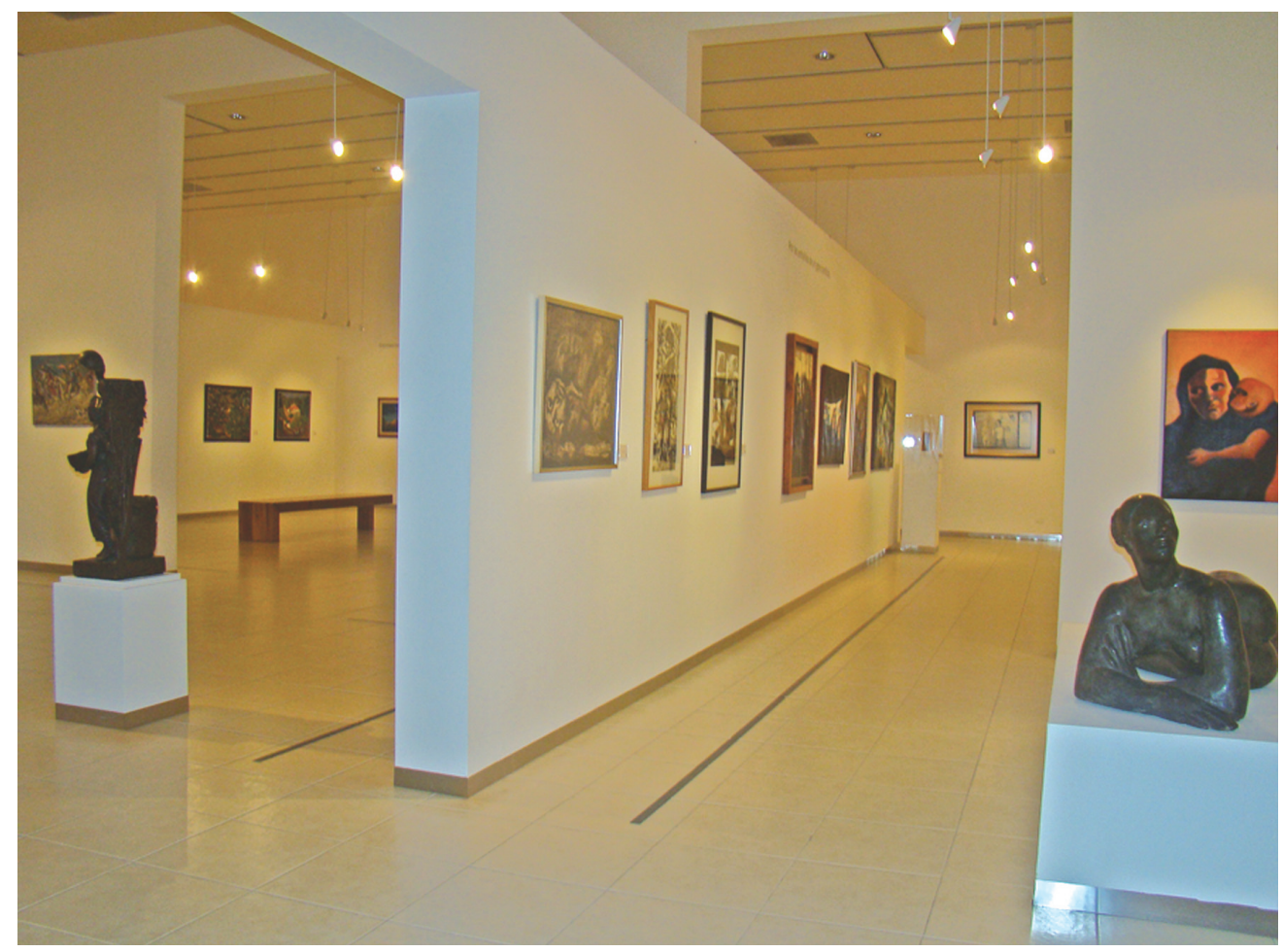

Sala de exhibición permanente, Marte

2004, inaugurar las instalaciones del Marte en un acto sin precedentes en la vida cultural de nuestro país, la noche del 22 de mayo de 2003. Es de destacar el valioso y oportuno apoyo que él brindo al proyecto. Hoy, como ciudadano, sigue colaborando.

Al día siguiente de su solemne apertura, los visitantes empezaron a llegar atraídos por las exposiciones de su jornada inaugural, consistentes en la Suitte Vollard de Pablo Picasso, "Julia Díaz. La herencia de sus sueños", "Diálogo entre artistas, pintura latinoamericana" y "Puntos Cardinales 1900-1992. Momentos clave del arte salvadoreño del siglo XX", cuyo curador fue Luis Croquer. Esta exhibición - estructurada en forma temática - se convirtió desde un primer momento en motivo de amplias discusiones y fijó, en lo que al arte salvadoreño se refiere, una nueva forma de verlo, estudiarlo y valorarlo. Esta muestra se cerró en el 2007, para dar paso a "ReVisiones, encuentros con el arte salvadoreño", que fue inaugurada el 18 de mayo de ese año y cuyo curador fue Jorge Palomo. Está previsto que esta exposición cierre a finales de 2011. 
Desde el día de su inauguración, que marca el compromiso de mantener abiertas las puertas de esta nueva institución cultural, miles de personas han visitado el museo. Hasta el 22 de mayo del presente año, fecha de nuestro sexto aniversario, 236.833 personas nos han visitado. Entre estas se destacan las niñas, niños y jóvenes estudiantes que representan más del $40 \%$ de esa cantidad, y que han sido atendidos gratuitamente y participado de nuestros programas de "Visitas guiadas" y en los "Talleres de arte". Estos programas forman parte del proyecto educativo del museo, siendo una de nuestras prioridades ya que estamos empeñados en formar nuevas audiencias. Desde el 18 de mayo de 2008, en ocasión de la celebración del "Día Internacional de los Museos" y con motivo de nuestro quinto aniversario, abrimos gratuitamente los días domingos. Este beneficio a la familia salvadoreña nos ha permitido atender a más de 10 mil personas durante este tiempo.

Para mantener el interés y garantizar al público que siempre hay algo nuevo por descubrir hemos presentado un rico y variado programa de exposiciones, nacionales e internacionales, a la vez que hemos desarrollado una serie de actividades complementarias que han propiciado el encuentro de la comunidad artística nacional y del público interesado con los especialistas, curadores y artistas que nos han visitado. De esta manera el museo, más allá de sus exposiciones, se convierte en un espacio de estudio y reflexión de todos los aspectos que inciden en el desarrollo artístico y cultural de nuestro país.

Sin embargo, el compromiso de la institución va mas allá, y desde un principio ha dado especial énfasis a sus programas educativos, implantando, como complemento a los programas mencionados (visitas guiadas y talleres), un programa de capacitación docente que nos ha permitido atender a cerca de 500 maestras y maestros de todo el país. Este programa, durante el presente año, cuenta con el apoyo del Ministerio de Educación. Como consecuencia, el museo vive y hace realidad el compromiso asumido por la Asociación, en el sentido de crear y mantener una institución abierta, dinámica y al servicio de la comunidad.

Conscientes de que este es el principio de un largo recorrido y de que los retos son grandes, hemos empezado a saldar cuentas pendientes que nuestro país tiene con el arte y sus artistas. Para lograrlo, es prioritario investigar, documentar y difundir el trabajo de nuestros maestros. Y ese compromiso ineludible nos ha permitido presentar las exposiciones de Julia Díaz (1917-1999), José Mejía Vides (1903-1993), Rosa Mena Valenzuela (1913-2004), Carlos 


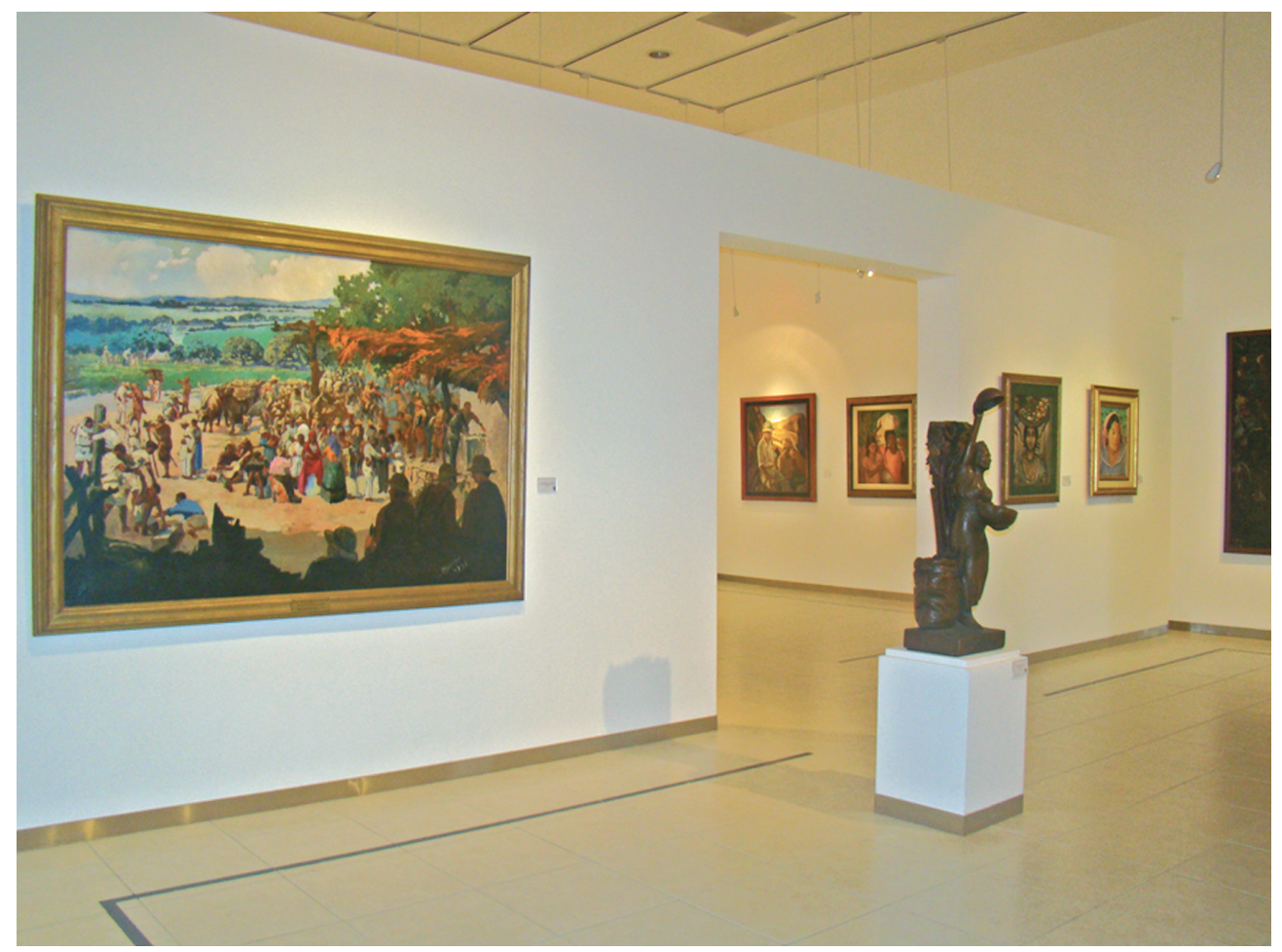

Sala de exhibición permanente, Marte

Cañas (1924), Toño Salazar (1897-1986), Salvador Salazar Arrué Salarrué, (1899-1975), Raúl Elas Reyes (1918-1997). A esta lista tenemos que sumar la exposición "Realidades y expresiones: Tendencias de la pintura salvadoreña (1970-1992)". En los próximos años continuaremos sumando los nombres de otros maestros que son figuras importantes en la escena y en la historia nacional. Sin prisas, pero con objetivos claros, abarcaremos el amplio espectro de la plástica nacional para asegurarnos de que, en el futuro, sabremos quiénes somos y de dónde venimos, porque, en el presente, aceptamos el reto de documentar nuestro pasado.

Hasta la fecha hemos publicado once catálogos. El último es el que registra, de mayo 2003 a mayo 2009, los seis años del programa "Artista del mes", que contiene la biografía revisada y actualizada de 69 artistas salvadoreños. Este libro - estamos seguros - será de gran beneficio para los maestros y los estudiantes de nuestro país. Simultáneamente a esta labor hemos presentado importantes exposiciones internacionales, haciendo posible para muchos salvadoreños observan las obras originales de Rembrandt, Picasso, Miró, Dalí, 
Chagall y del muralista mexicano David Alfaro Sequeiros, para mencionar a seis maestros del arte universal.

Como parte de nuestro compromiso también hemos abierto espacios al arte contemporáneo y presentado notables exposiciones entre las que destacamos "Ecos y contrastes"; "Arte contemporáneo", de la Colección Cisneros y la celebración, en el 2006, de la "V Bienal de Artes Visuales del Istmo Centroamericano". Como apoyo permanente a los artistas jóvenes y emergentes de nuestro país en la actualidad desarrollamos el programa "Marte contemporáneo".

Hacia fuera también hemos proyectado el museo y el trabajo de nuestros artistas, en especial a Toño Salazar (1897-1986), el más universal de nuestros creadores, de quien presentamos su exposición, producida por el museo en el 2005, en París, en la Casa de América Latina, y en Panamá en el Museo de Arte Contemporáneo (2007). También hemos facilitado sus obras para el Museo Nacional Centro de Arte Reina Sofía, España (2003) y para el Museo Nacional de Arte de México (2009).

Es importante destacar que nuestra colección se va enriqueciendo con el paso de los años y que hoy contamos como acervo 258 obras, que cuidamos con especial esmero y conservamos en condiciones adecuadas, gracias a los aportes recibidos en el 2007 del programa Fondos del Embajador para la Preservación Cultural del Gobierno de los Estados Unidos y del Centro Cultural del Banco Interamericano de Desarrollo.

Todo lo anterior demanda grandes esfuerzos y muchos recursos. Por esa razón, y por el compromiso con nuestro país, su arte y sus artistas, que son la razón de ser del Museo de Arte de El Salvador, trabajamos día a día para mantener el nivel de calidad de todos los servicios que ofrecemos y para ser autofinanciables.

Esa tarea nos ha llevado a diversificar las fuentes de financiamiento y a reportar periódicamente lo que hacemos, ya que es la mejor forma de demostrar - a quienes nos ayudan - que los fondos recibidos son utilizados de la mejor manera posible y que benefician a muchos salvadoreños que, al igual que nosotros, piensan que el arte debe ser integrado a nuestras vidas. Esperamos que cada día más y más compatriotas sean parte de este gran esfuerzo que es, y que debe continuar siendo, un esfuerzo compartido. 


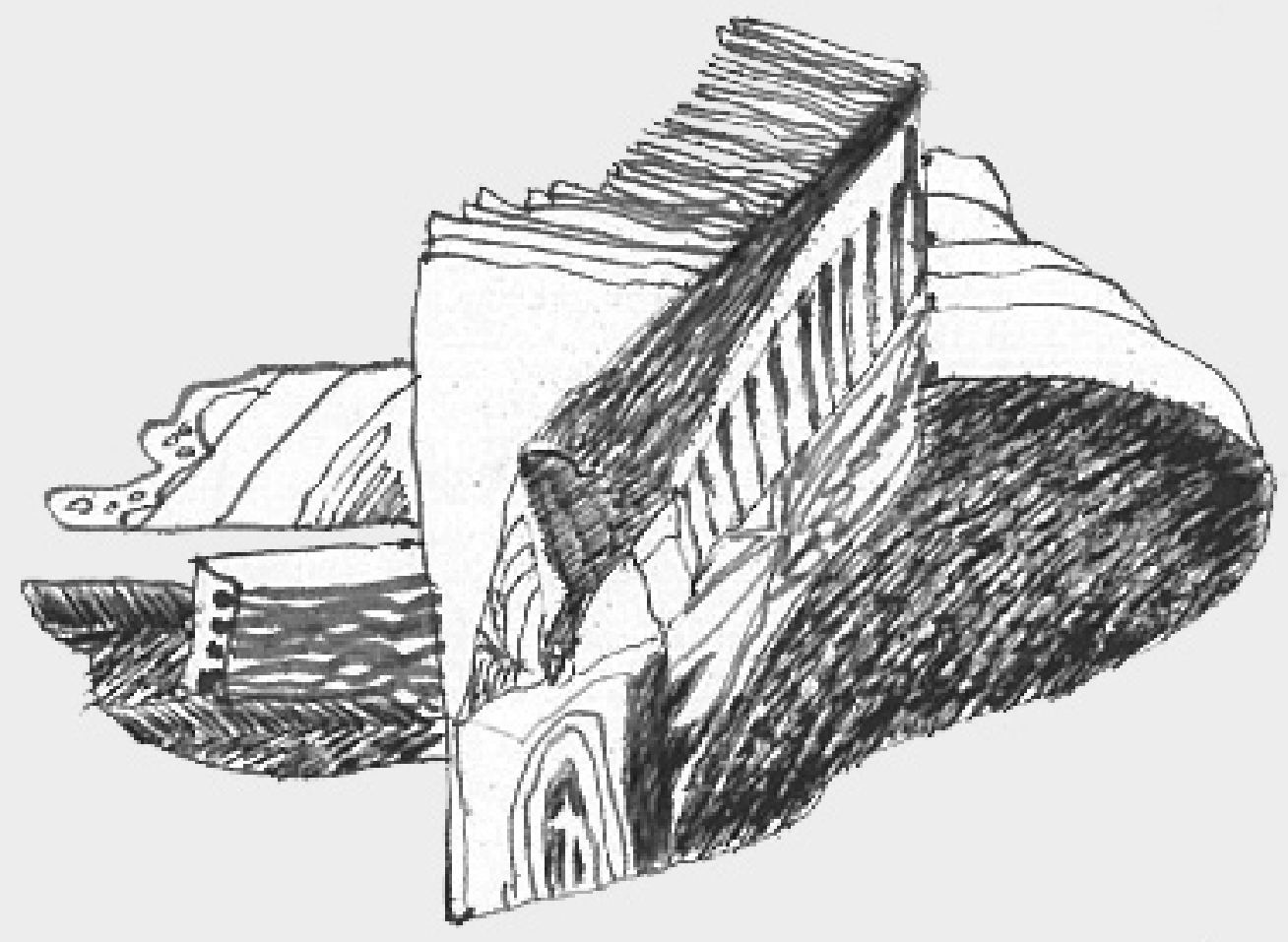




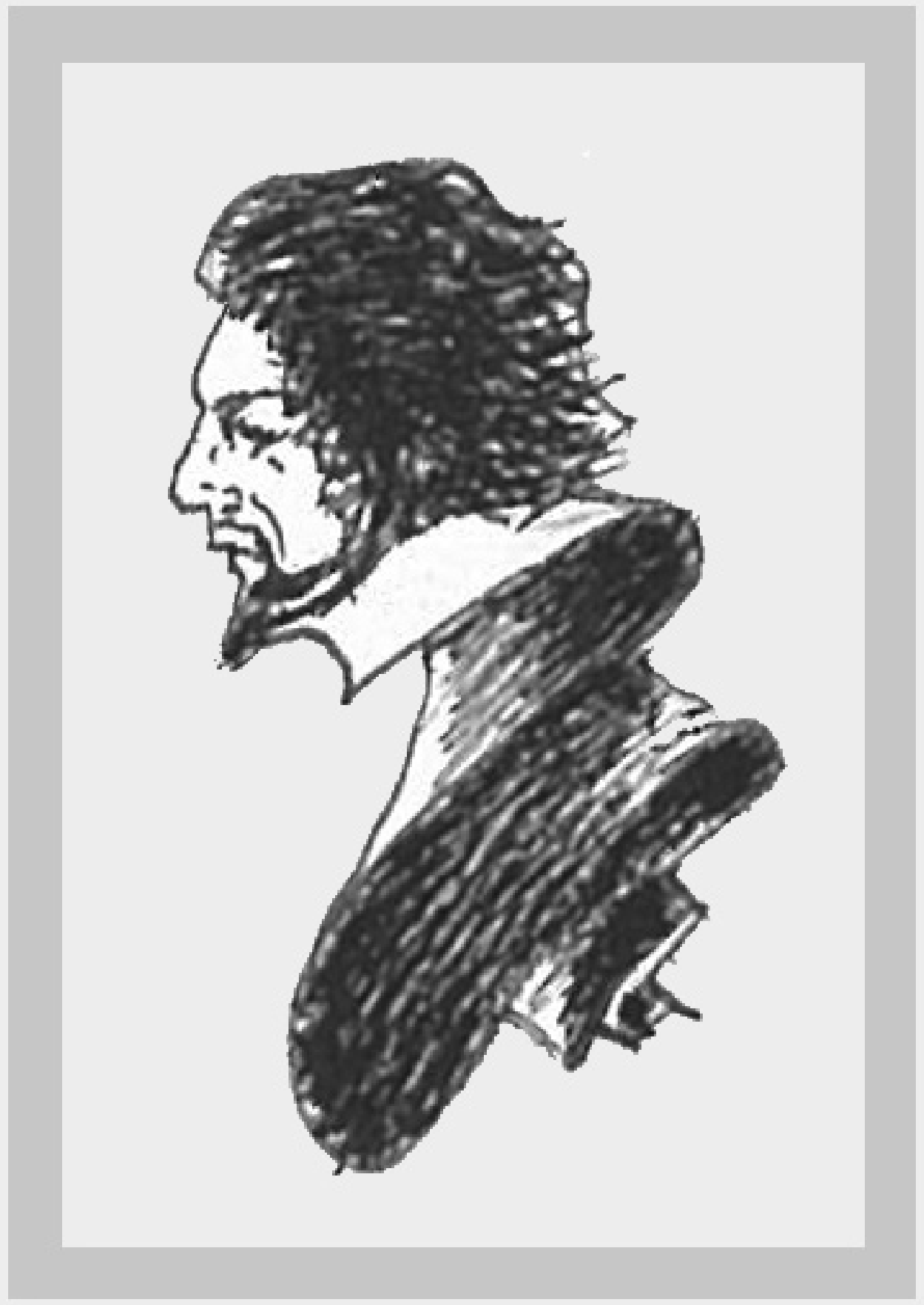

